\title{
Characteristics of hazardous oil \& liquid fuel waste discharged from various industries
}

\author{
Sun-Kyoung Shin ${ }^{\star}$, Seong-Kyeong Jeong, Woo-II Kim, Jeon Tae-Wan, Young-Yeul Kang, \\ Jin-Mo Yeon, Yoon-A Cho and Min-Sun Kim \\ National Institute of Environmental Research, Incheon 404-170, Korea
}

(Received June 4, 2013; Revised July 29, 2013; Accepted July 29, 2013)

\section{폐유 및 액상연료 공정 폐기물에서 무기물질류의 함량특성 신선경` · 정성경 · 김우일 · 전태완 · 강영렬 · 연진모 · 조윤아 · 김민선 \\ 국립환경과학원 환경자원연구부 자원순환연구과 (2013. 6. 4. 접수, 2013. 7. 29. 수정, 2013. 7. 29. 승인)}

\begin{abstract}
This study was performed to investigate the contents characteristics of hazardous oil wastes and wastes of liquid fuels from different industrial process. In order to establish a hazardous waste list, samples of various industrial discharge have been analyzed for 16 non-regulated inorganic hazardous substances (i.e., $\mathrm{Cu}, \mathrm{Pb}, \mathrm{Cd}$, $\left.\mathrm{CN}, \mathrm{Hg}, \mathrm{As}, \mathrm{T}-\mathrm{Cr}, \mathrm{Cr}^{6+}, \mathrm{Sb}, \mathrm{Ni}, \mathrm{F}, \mathrm{V}, \mathrm{Ba}, \mathrm{Zn}, \mathrm{Be}, \mathrm{Se}\right)$. In more detail, hazardous waste samples including waste hydraulic oils, waste engine, gear and lubricating oils, waste insulating and heat transmission oils, bilge oils, oil/water separator contents processing were collected from 37 workplaces and analyzed. We observed that the most of the inorganic substances exceeded the proposed criteria in many samples. Especially the concentration of $\mathrm{Sb}$ in heat transmission oil, bilge oil and gear \& lubricating oils were ranged from 6 to 419 $\mathrm{mg} / \mathrm{kg}$ whereas the proposed criteria is $50 \mathrm{mg} / \mathrm{kg}$. The assessment result of hazardous waste in Korea according to the EWC showed that the out of 24 processes, 16 belongs to absolute entry and 8 belongs to mirror entry. In conclusion, we expect the outcome of this study to align the classification system of hazardous waste management in South Korea with international legislations, and consequently contribute to reduce environmental pollution as well as health risks by toxic wastes.

요 약: 국내 유해폐기물의 적정 관리를 위해 폐유 및 액상연료 공정에서 발생한 폐기물 중 규제 무기 물질류의 배출특성을 조사하였다. 사업장은 올바로시스템에 등록된 폐기물 배출업체를 대상으로, 유럽폐 기물 분류체계(EWC, European Waste Catalogue)의 폐유 및 액상연료 공정(EWC 13)과 유사한 폐기물 발 생업체를 선정하였다. 조사대상 사업장 37 개 업체를 현지 방문하여 원료, 생산제품, 생산 공정, 폐기물 의 종류 및 배출과정을 조사하고 생산 공정에서 배출되는 51 개의 폐기물을 채취하여 무기물질류 16 항 목 $\left(\mathrm{Cd}, \mathrm{Pb}, \mathrm{Cu}, \mathrm{Hg}, \mathrm{As}, \mathrm{CN}, \mathrm{Cr}, \mathrm{Cr}^{6+}, \mathrm{Ba}, \mathrm{Be}, \mathrm{F}, \mathrm{Ni}, \mathrm{Sb}, \mathrm{Se}, \mathrm{V}, \mathrm{Zn}\right)$ 에 대한 함량분석을 수행하였다. 분석 결과, 모든 공정에서 발생된 폐기물에서 주로 $\mathrm{Sb}$ 가 검출되었고, $6 \sim 419$ (평균 98 ) $\mathrm{mg} / \mathrm{kg}$ 의 농도 범위를 나
\end{abstract}

^ Corresponding author

Phone : +82-(0)32-560-7503 Fax : +82-(0)32-568-1656

E-mail : shinsun1004@korea.kr 
타내었다. EWC 판정 절차를 통해 국내 폐유 및 액상연료 공정에서 발생된 폐기물을 판정한 결과, $\mathrm{EWC}$ 중분류 24 공정 중 절대유해폐기물로 분류해서 관리해야할 공정은 16 개, 상대유해폐기물로 관리가 필요 한 공정은 8 개로 판단되었다. 폐기물의 배출특성을 통해 유해물질 함유 자료를 확보하고 폐기물 목록에 대한 데이터베이스를 구축함으로써 유해폐기물의 안전처리를 통한 환경오염을 방지할 수 있을 것으로 기대된다.

Key words: hazardous waste classification, contents analysis, designated waste, oil waste, liquid fuel waste

\section{1. 서 론}

최근 $\mathrm{OECD}($ Organization for Econonic Cooperation and Development), 일본, 독일 등은 자원과 에너지를 확보하기 위한 수단으로 기후문제와 연계한 폐기물의 자원순환 정책을 적극적으로 추진하고 있다. 또한 런 던협약, WEEE(Waste Electrical and Electronic Eqinent) 등의 국제기구는 환경오염을 예방하고 폐기물의 적정관리를 위한 국제환경 규제를 강화하고 있는 추 세이다. 이와 같은 국제적 추세를 반영한 국내 폐기물 관리체계 변화의 필요성을 고려하여 2008년부터 유해 폐기물 배출특성 조사연구 사업이 추진되고 있다. ${ }^{1}$ 국 내 사업장에서 발생되는 폐기물의 배출원별 특성을 파악함으로써 폐기물 발생 억제, 적정 재활용, 물질회 수 및 안전처리를 통해 자원의 순환과정을 환경 친화 적으로 관리하는 자원순환의 개념을 폐기물 관리 정 책에 도입하였다. ${ }^{2}$

우리나라는 지정폐기물(Specified Waste)의 안전처 리를 통한 폐자원의 활성화를 위해「폐기물관리법」 의 지정폐기물을 11 종으로 대분류하고 70 여종으로 세분화하여 폐기물을 관리하고 있으나, 미국 및 유럽 연합은 발생공정 - 폐기물 성상, 유해특성 등에 의해 유해폐기물을 보다 세분화하여 관리하고 있다. ${ }^{3-5}$

우리나라도 이와 같은 국제적 동향에 발맞추고, 폐기물 분류를 업종별 - 공정별, 유해성분, 유해특성 등에 의해 명확히 분류하여 유해폐기물 목록을 세분 화함으로써 폐기물 분류의 오류를 방지하고 분류번 호에 의해 폐기물 특성을 알 수 있도록 하는 것이 필요하다.

따라서 본 연구에서는 폐기물이 발생하는 업종 중 EWC(European Waste Catalogue) 13(폐유 및 폐액상 연료 공정)에 한하여 유해폐기물의 발생특성을 조사 하여 유해폐기물을 목록화하는 방안에 대하여 조사하 였다. 이를 위하여 EU 등 선진국의 유해폐기물 목록 을 조사하여 국내 공정별 발생폐기물 조사대상 사업
장을 선정하고, 해당공정의 유해폐기물 시료를 51 개 채취하여 유해물질의 함량을 분석함으로써, 유해폐기 물 목록을 작성하였다.

\section{2. 연구내용 및 실험방법}

\section{1. 사업장 선정 및 시료채취}

국내 폐유 및 액상연료 업종에서 배출되는 지정폐 기물 시료를 채취하기 위해 올바로 시스템(Allbaro System $)^{6}$ 에 등록되어 있는 지정폐기물 배출목록 등을 기초로 하여 EWC(European Waste Catalogue) 13 목록 에 해당하는 표본사업장을 선정하였다. 2011년도 올 바로 시스템에 등록된 24만 건의 지정폐기물 배출기 록 중 폐유 및 액상연료 업종에서 배출되는 1 만 5 천 건의 지정폐기물 발생현황에 따라 지정폐기물 배출업 소를 분류하고, 약 100 여개 사업장을 조사 대상으로 선정하였다. 본 연구에서 총 채취된 시료의 수는 51 개로, 폐유 및 액상연료 업종 중에서 중분류된 7 개 업종의 37 소 사업장을 선정하였다. 시료채취는 사업장 을 직접 방문하는 것을 원칙으로 하였고 배출특성 파 악을 위한 업체의 현황 자료(생산품, 제품 생산공정, 원료 투입량, 폐기물의 종류 및 발생량, 처리현황, 폐 기물 분석자료) 등을 추가로 조사하였다. 시료 채취는 2012년 6 10월에 이루어 졌으며, 평균 1.38 개(시료/ 사업장)의 시료가 채취 되었다. 시료의 종류 및 시료 채취 현황은 Table 1 과 같으며 채취방법은 폐기물공정 시험기준(ES 06130, 2010)을 준용하여 수행하였다.

\section{2. 분석방법}

분석방법은 국립환경과학원의「폐기물 중 미규제 유해물질 시험방법 표준화에 관한 연구 ${ }^{8}$ 를 근거로 하여, 총 51 건을 분석하였다. 고상폐기물 시료는 $0.5 \sim 5 \mathrm{~mm}$ 로 체질하여 균일하게 하였고, 분석항목은 규제 7 항목 $\left(\mathrm{Cu}, \mathrm{Cd}, \mathrm{Cr}^{6+}, \mathrm{Pb}, \mathrm{Hg}, \mathrm{As}, \mathrm{CN}\right)$ 과, 미규제 9항목 $(\mathrm{Sb}, \mathrm{Ni}, \mathrm{F}, \mathrm{V}, \mathrm{Ba}, \mathrm{Zn}, \mathrm{Be}, \mathrm{Se}, \mathrm{Cr})$ 이며 자세한 


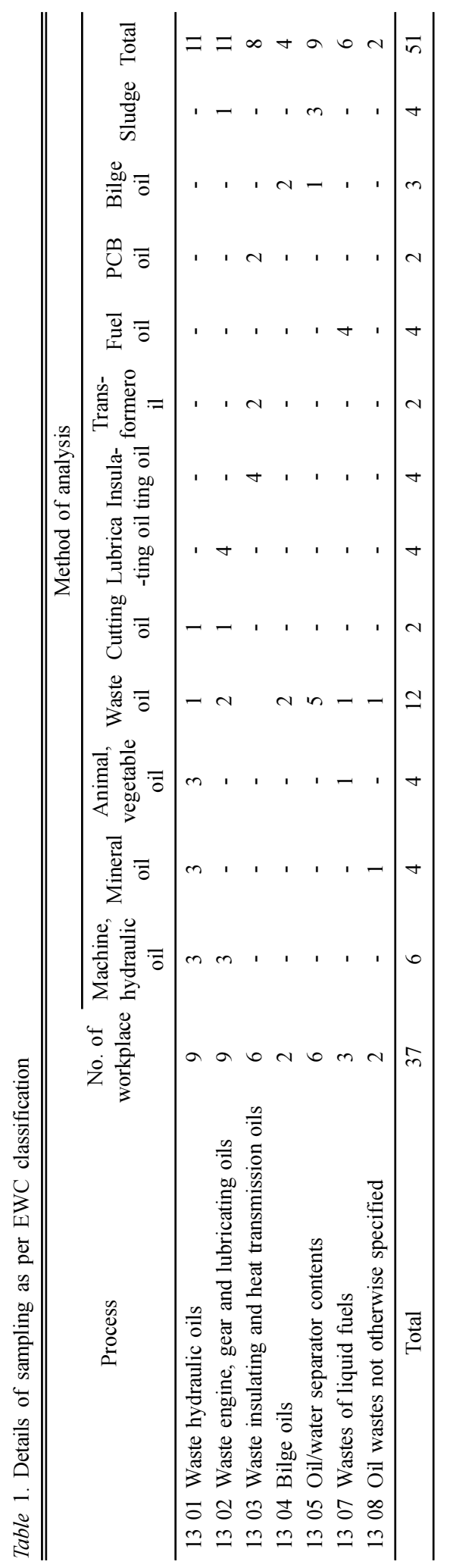


Table 2. analytical method for inorganic substance

\begin{tabular}{ll}
\hline \hline \multicolumn{1}{c}{ Inorganic substance } & Digestion \\
\hline $\mathrm{Ba}, \mathrm{Be}, \mathrm{Cr}, \mathrm{Ni}, \mathrm{Sb}, \mathrm{V}, \mathrm{Zn}, \mathrm{Cd}, \mathrm{Cu}, \mathrm{Pb}$ & $\cdot$ ES 6902.1 (Inductively Coupled Plasma Atomic Emission Spectrometry) \\
$\mathrm{CN}$ & $\cdot \mathrm{ES} 6902.1$ \\
$\mathrm{Hg}$ & $\cdot \mathrm{ES} 6907.1$ (Hg-Cold Vapor Atomic Absorption Spectrometry) \\
$\mathrm{F}$ & $\cdot$ ES 6904.2 (F-Ultraviolet Visible Spectrophotometry) \\
$\mathrm{As}, \mathrm{Se}$ & $\cdot \mathrm{ES} 6903.1$ (Inductively Coupled Plasma Atomic Emission Spectrometry) \\
$\mathrm{Cr}^{6+}$ & $\cdot \mathrm{ES} 6906.1\left(\mathrm{Cr}^{6+}\right.$-Ultraviolet Visible Spectrophotometry) \\
\hline
\end{tabular}

항목별 전처리 방법은 Table 2에 나타내었다.

위 16 항목의 전처리는 마이크로웨이브(US/Mars5, Cem Innovators)를 이용하여 질산(Wako, 61\%)분해 후 여과지(Adventec 5B, $4 \mu \mathrm{m}$ )를 사용하였다. $\mathrm{Ba}, \mathrm{Be}, \mathrm{Cr}$, $\mathrm{Ni}, \mathrm{Sb}, \mathrm{V}, \mathrm{Zn}, \mathrm{Cd}, \mathrm{Cu}, \mathrm{Pb}$ 항목분석은 ICP-OES (Jobin Yvon, US/Ultima 2)를 이용하였고, 표준액으로는 다성 분 표준물질(Plasmacal)을 사용하였다. AAS (Varian $\mathrm{AA}, 280 \mathrm{FS}$ )를 사용하여 $\mathrm{Hg}, \mathrm{As}, \mathrm{Se}$ 를 분석하였고, 사 용한 산화제로 염산(Wako, 37\%), 환원제는 $\mathrm{NaBH}_{4}$ (Wako, 95\%), $\mathrm{NaOH}$ (Crown Guaranteed Reagents, 96\%) 를 사용하였고, $\mathrm{AAS}$ 용 표준액은 Accutrace사 표준물 질을 이용하였다. $\mathrm{CN}$ 은 시안증류장치 (Gergardt사 $\mathrm{De} /$ Vapodest 10)를 사용하여 전처리 후 UV-VIS (Bio-Tek, Uvikon XL Plus)로 분석하였고, F (Gergardt사 De/ Vapodest 10)는 란탄 알리자닌-자외선/가시선 분광광 도법(ES 6904. 2), $\mathrm{Cr}^{6+}$ 은 자외선/가시선 분광광도법을 통하여 UV-VIS로 분석하였다.

\section{3. 결과 및 고찰}

폐기물관리법에서 관리되고 있는 국내 유해물질 기 준은 동법 시행규칙 별표 1(지정폐기물에 함유된 유 해물질)에 해당하는 규제 무기물질 7 종 $\left(\mathrm{CN}, \mathrm{Cr}^{6+}, \mathrm{Cu}\right.$, $\mathrm{Cd}, \mathrm{Pb}, \mathrm{As}, \mathrm{Hg}$ )의 용출 기준만으로 관리되고 있다. 따라서 본 연구에서는 국립환경과학원에서 선수행된 「지정폐기물 중 미규제 유해물질 규제항목 확대에 관 한 연구(I), (II)」9-10 함량 기준과 비교 검토하였다. 선 수행된 보고서에는 선진국 등의 함량규제 기준과 국 내 사업장 폐기물 분석결과를 바탕으로 기준을 제안 하고 있다.

\section{1. 규제대상 무기물질의 함량특성}

총 51건의 폐기물 시료에 대하여 Table 2에 제시된 8 개 규제대상 무기물질류 항목의 함량 분석을 수행 하였으며, 그 결과를 Table 3과 Fig. 1에 나타내었다.
규제대상 무기물질류의 함량분석 결과, $\mathrm{EWC} 13$ 01 (폐유압유) 공정의 9 개 시료에서 $\mathrm{Cd}$ 과 $\mathrm{Cu}$ 의 농도 가 제안 기준인 $5 \mathrm{mg} / \mathrm{kg}$ 를 초과하였다. 특히 냉연과 정에서 발생한 유압유에서 $\mathrm{Cu}$ 의 농도 $(1,207 \mathrm{mg} / \mathrm{kg})$ 가 제안기준의 240 배 이상으로 조사되었고, 이는 구리를 제련하는 공정에서 발생한 오니를 함유한 폐유로 인 한 결과인 것으로 판단된다. ${ }^{11-12} \mathrm{EWC} 13$ 02(폐엔진오 일, 폐윤활유)에 해당하는 지정폐기물 처리업체에서 발생한 윤활유에서는 규제대상 항목 중 $\mathrm{Cd}(61 \mathrm{mg} /$ $\mathrm{kg}$ )만 제안기준을 초과하였다. 해당 공정은 금속을 절 삭할 때 사용한 절삭유와, 기계를 돌릴 때 사용한 터 빈유 등에서 중금속이 발생된 것으로 판단된다. $\mathrm{EWC}$ 13 03(폐절연유, 폐열전달유)공정의 시료는 대부분 변 압기에서 발생한 절연유로, 중금속 함량분석결과 $\mathrm{Cd}$ $496 \mathrm{mg} / \mathrm{kg}, \mathrm{Cu} 430 \mathrm{mg} / \mathrm{kg}, \mathrm{Pb} 102 \mathrm{mg} / \mathrm{kg}, \mathrm{CN} 366$ $\mathrm{mg} / \mathrm{kg}$ 의 농도로 나타나 $\mathrm{Cr}^{6+}, \mathrm{Hg}$ 를 제외한 모든 항목 에서 제안 기준을 초과 하는 것으로 조사되었다. 해당 공정 대부분의 시료는 절연유로, 광유가 $87 \%$ 로 이루어 져 있어서 여러종류의 무기물질이 함유되어진 것으로 판단된다. ${ }^{13} \mathrm{EWC} 13$ 04(선저유) 공정 중 일부시료에서 는 $\mathrm{Cd}$ 에서만 6배 초과 하였고, $\mathrm{EWC} 13$ 05공정은 유수 분리시 발생한 폐기물로 특히 $\mathrm{Cu}(414 \mathrm{mg} / \mathrm{kg})$ 의 농도 가 높게 나타났다. 이는 기름보관 탱크를 청소하고 난 후 발생한 폐기물로, 원인규명이 어려웠고 차후 연구를 통해 분석이 필요한 것으로 판단된다. 그리고 액체 연 료에서 발생한 폐기물 공정(EWC 13 07)에서는 $\mathrm{Cd}$ 이 $55 \sim 665,815 \mathrm{mg} / \mathrm{kg}, \mathrm{Cu}$ 가 $1,846 \mathrm{mg} / \mathrm{kg}$ 수준으로 검출되 었으며, $\mathrm{EWC} 1308$ 공정에 해당하는 2 개의 시료에서 는 $\mathrm{Cr}^{6+}$ 만 제안 기준인 $20 \mathrm{mg} / \mathrm{kg}$ 를 초과 하였다.

EWC 13(폐유 및 액상연료 폐기물)공정의 특성상 대부분 시료는 폐유가 주성분인 것으로 판단되며, 분 석결과 또한 폐유의 성상과 비슷하였다.

\section{2. 미규제대상 무기물질의 함량특성}

폐유 및 액상연료 공정(EWC 13)에 해당하는 폐기물 


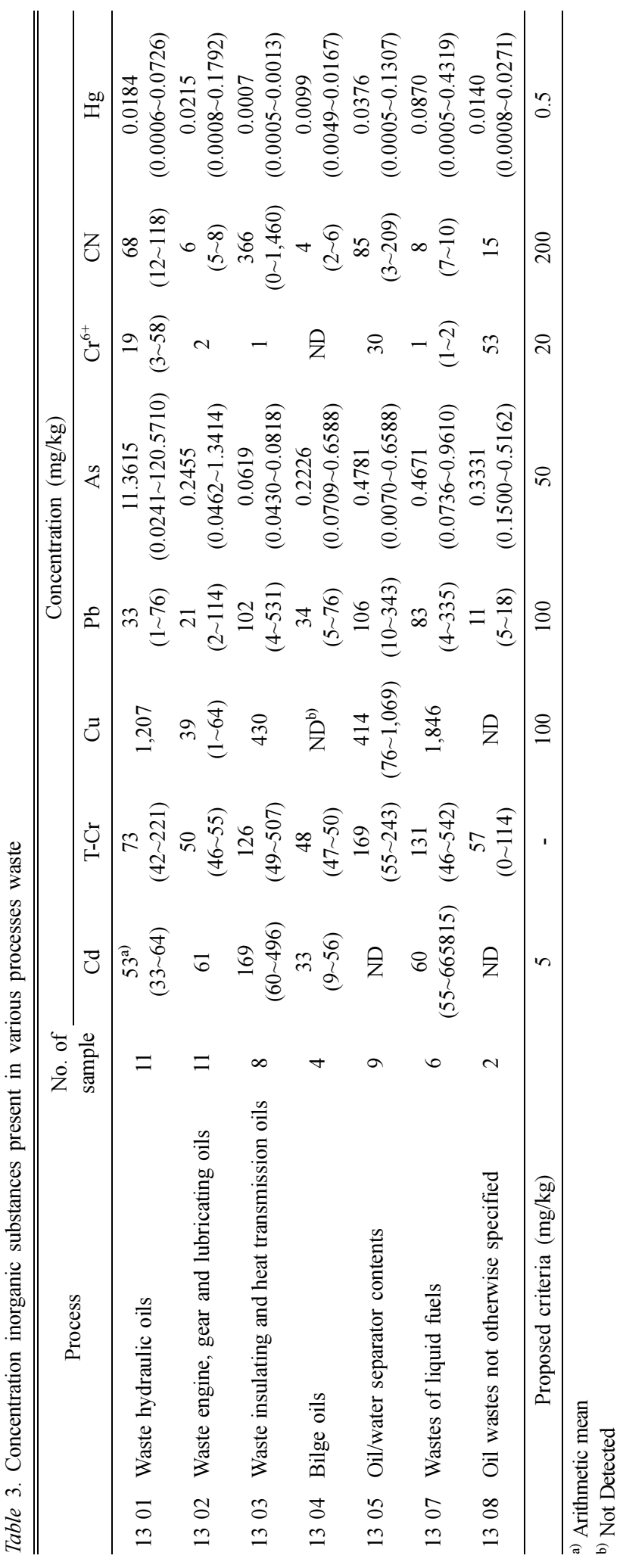



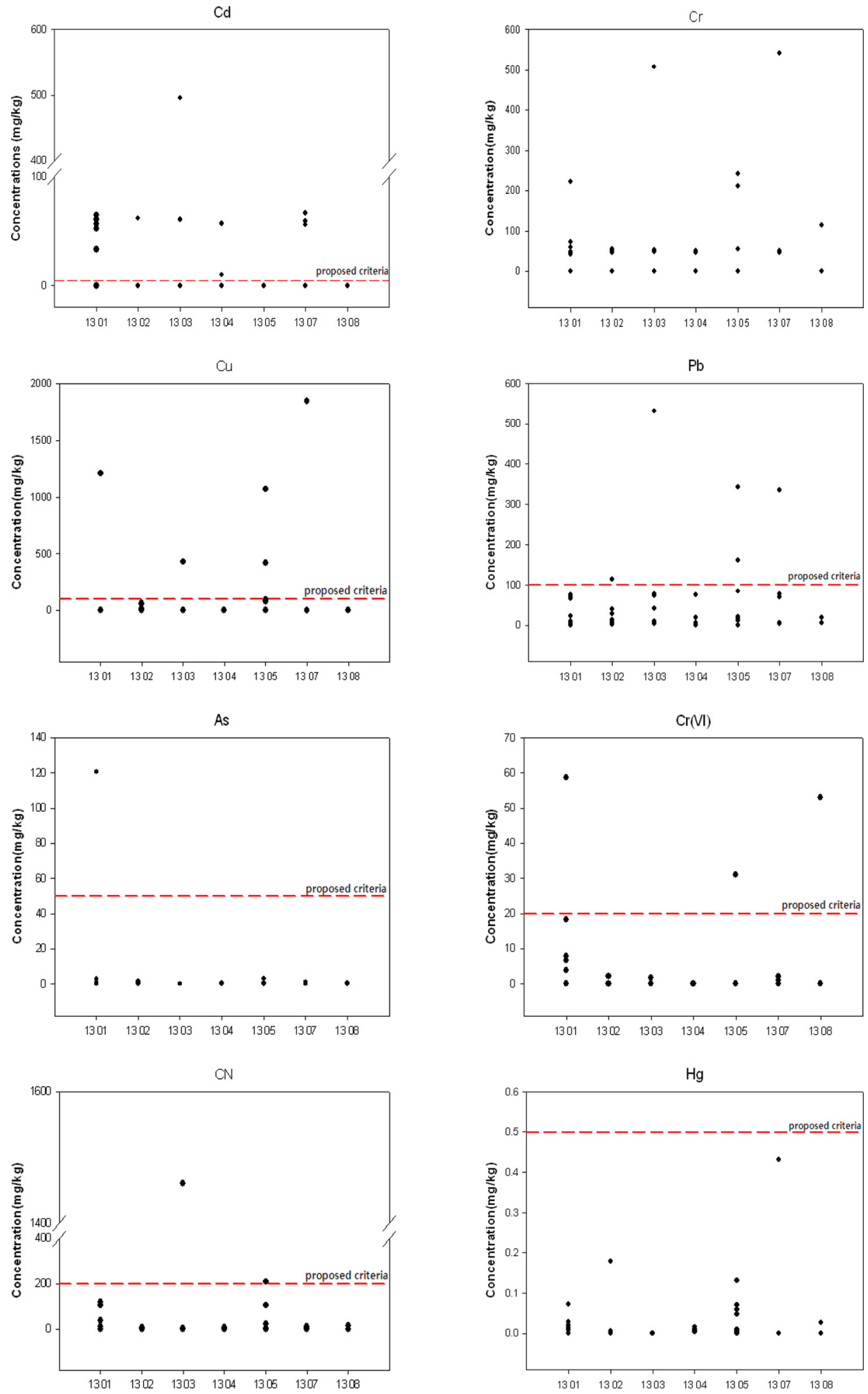

Fig. 1. contents concentration of inorganic substances as per EWC code (regulation). 
$\mathrm{Ba}$

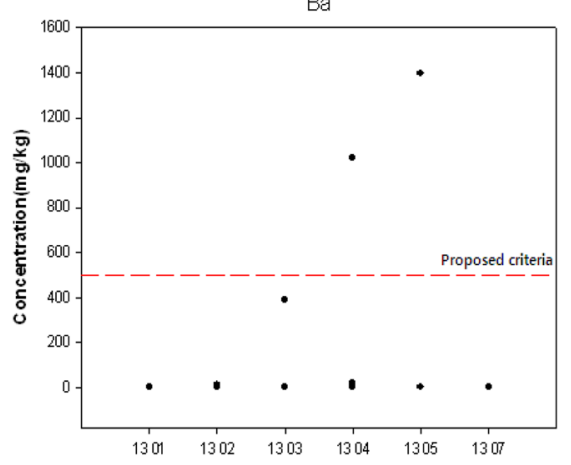

Ni

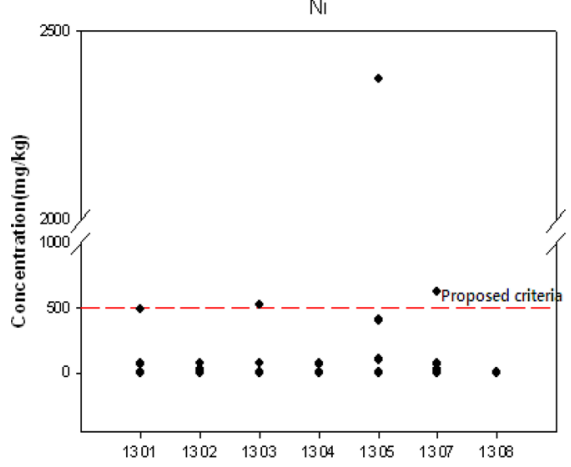

Se

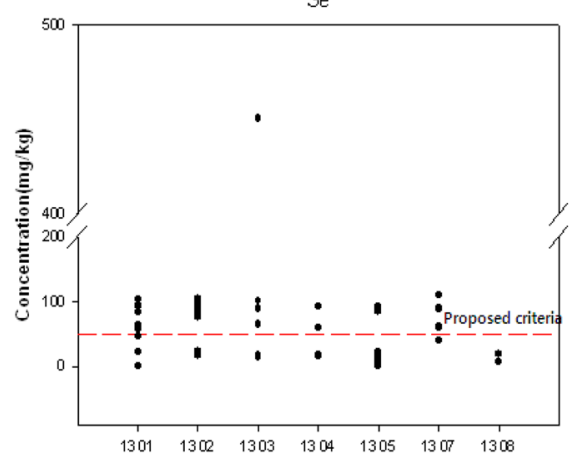

$\mathrm{Zn}$

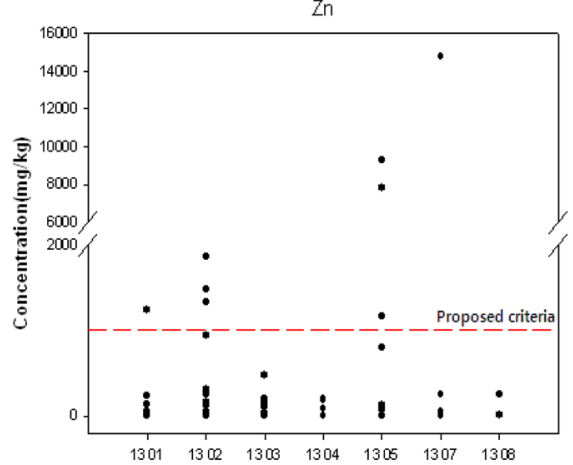

Be

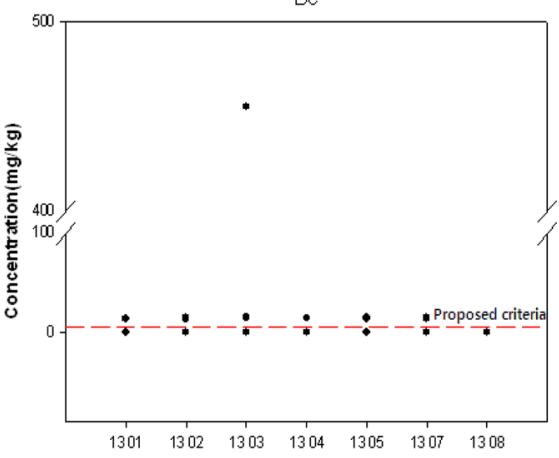

$\mathrm{Sb}$
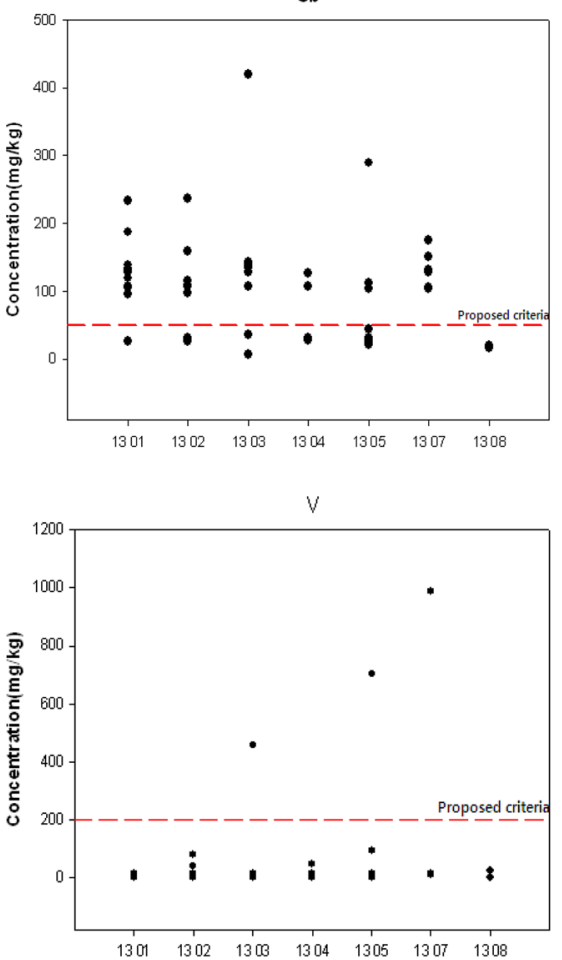

F

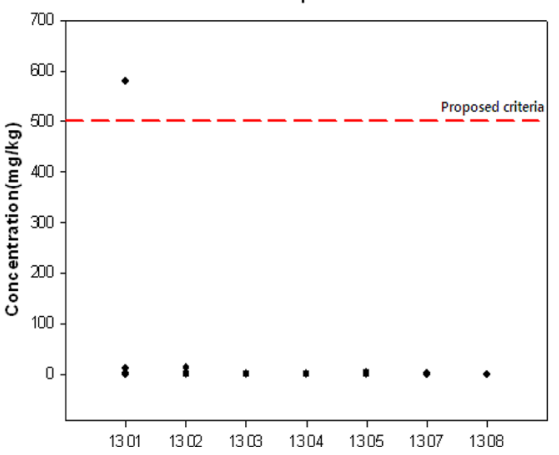

Fig. 2. contents concentration of inorganic substances as per EWC code (regulation) 


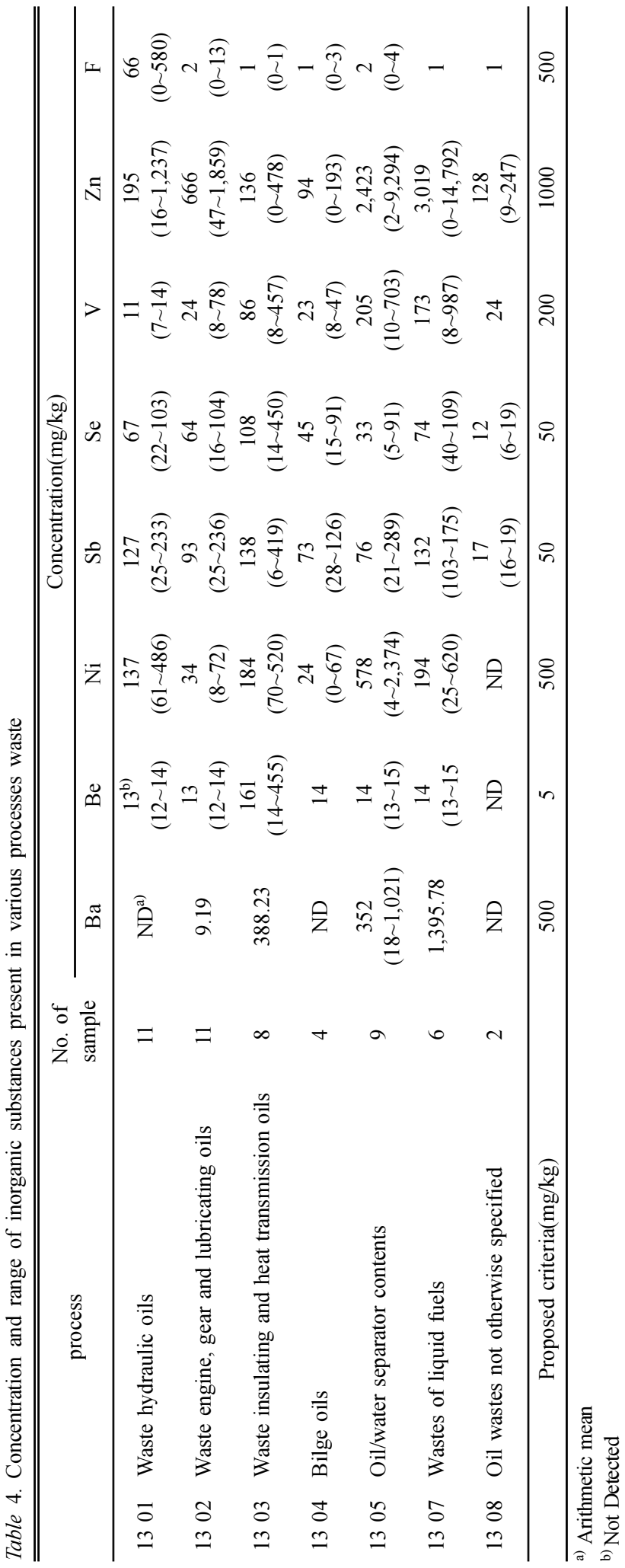


Table 5. processes listed in the hazardous waste classification (draft)

\begin{tabular}{|c|c|c|c|c|c|}
\hline Category & Sub-category & Code & EU list of waste & $\begin{array}{l}\text { Inorganic substances } \\
\text { exceeding standards }\end{array}$ & Evaluation \\
\hline \multirow{24}{*}{13} & \multirow{6}{*}{$\begin{array}{c}1301 \\
\text { waste hydraulic oils }\end{array}$} & 130101 & Hydraulic oils, containing PCBs & $\mathrm{Cd}, \mathrm{Be}, \mathrm{Sb}, \mathrm{Se}, \mathrm{Zn}$ & $\mathrm{A}^{\mathrm{a})}$ \\
\hline & & 130110 & Mineral based non-chlorinated hydraulic oils & $\mathrm{Cd}, \mathrm{Sb}, \mathrm{Se}$ & A \\
\hline & & 130111 & Synthetic hydraulic oils & $\mathrm{Be}, \mathrm{Sb}, \mathrm{Se}$ & $\mathrm{M}^{\mathrm{B})}$ \\
\hline & & 130112 & Readily biodegradable hydraulic oils & $\mathrm{Cd}, \mathrm{Sb}, \mathrm{Se}$ & A \\
\hline & & 130113 & Other hydraulic oils & $\mathrm{Sb}, \mathrm{Se}, \mathrm{F}$ & M \\
\hline & & 130204 & $\begin{array}{l}\text { Mineral-based chlorinated engine, gear and } \\
\text { lubricating oils }\end{array}$ & $\mathrm{Be}, \mathrm{Sb}, \mathrm{Se}$ & M \\
\hline & \multirow{3}{*}{$\begin{array}{c}1302 \\
\text { waste engine, gear and } \\
\text { lubricating oils }\end{array}$} & 130205 & $\begin{array}{l}\text { Mineral-based non-chlorinated engine, gear } \\
\text { and lubricating oils }\end{array}$ & $\mathrm{Be}, \mathrm{Sb}, \mathrm{Se}$ & M \\
\hline & & 130206 & Synthetic engine, gear and lubricating oils & $\mathrm{Be}, \mathrm{Sb}, \mathrm{Se}, \mathrm{Zn}$ & M \\
\hline & & 130207 & $\begin{array}{l}\text { Readily biodegradable engine, gear and lubri- } \\
\text { cating oils }\end{array}$ & $\mathrm{Be}, \mathrm{Sb}, \mathrm{Se}$ & M \\
\hline & \multirow{5}{*}{$\begin{array}{l}1303 \\
\text { waste insulating and } \\
\text { heat transmission oils }\end{array}$} & 130208 & Other engine, gear and lubricating oils & $\mathrm{Cd}, \mathrm{Cu}, \mathrm{Be}, \mathrm{Sb}, \mathrm{Se}, \mathrm{Zn}$ & A \\
\hline & & 130301 & $\begin{array}{l}\text { Insulating or heat transmission oils containing } \\
\text { PCBs }\end{array}$ & $\mathrm{Cd}, \mathrm{Sb}, \mathrm{Se}$ & A \\
\hline & & 130307 & $\begin{array}{l}\text { Mineral-based non-chlorinated insulating and } \\
\text { heat transmission oils }\end{array}$ & $\mathrm{Cd}, \mathrm{Cu}, \mathrm{Pb}, \mathrm{Be}, \mathrm{Sb}, \mathrm{Se}$ & A \\
\hline & & 130308 & Synthetic insulating and heat transmission oils & $\mathrm{Cd}, \mathrm{Sb}, \mathrm{Se}$ & A \\
\hline & & 130310 & Other insulating and heat transmission oils & $\mathrm{CN}, \mathrm{Be}, \mathrm{Sb}, \mathrm{Se}$ & A \\
\hline & 1304 & 130401 & Bilge oils from inland navigation & $\mathrm{Cd}, \mathrm{Be}, \mathrm{Sb}, \mathrm{Se}$ & A \\
\hline & \multirow[t]{2}{*}{ bilge oils } & 130403 & Bilge oils from other navigation & $\mathrm{Cd}$ & A \\
\hline & & 130502 & Sludges from oil/water separators & $\mathrm{Pb}$ & A \\
\hline & \multirow{3}{*}{$\begin{array}{c}1305 \\
\text { oil/water separator } \\
\text { contents }\end{array}$} & 130506 & Oil from oil/water separators & $\begin{array}{l}\mathrm{Cu}, \mathrm{Pb}, \mathrm{Cr}^{6+}, \mathrm{CN}, \mathrm{Ba}, \\
\mathrm{Be}, \mathrm{Ni}, \mathrm{Sb}, \mathrm{Se}, \mathrm{V}, \mathrm{Zn}\end{array}$ & A \\
\hline & & 130507 & Oily water from oil/water separators & $\mathrm{Be}, \mathrm{Sb}, \mathrm{Se}, \mathrm{Zn}$ & M \\
\hline & & 130508 & $\begin{array}{l}\text { Mixtures of wastes from grit chambers and } \\
\text { oil/water separators }\end{array}$ & $\mathrm{Cu}, \mathrm{Be}, \mathrm{Ni}, \mathrm{Sb}, \mathrm{Se}, \mathrm{Zn}$ & $\mathrm{A}$ \\
\hline & \multirow{3}{*}{$\begin{array}{c}1307 \\
\text { wastes of liquid fuels }\end{array}$} & 130701 & Fuel oil and diesel & $\mathrm{Be}, \mathrm{Sb}, \mathrm{Se}$ & M \\
\hline & & 130702 & Petrol & $\begin{array}{l}\mathrm{Cd}, \mathrm{Cu}, \mathrm{Pb}, \mathrm{Ba}, \mathrm{Ni}, \\
\mathrm{Sb}, \mathrm{Se}, \mathrm{V}, \mathrm{Zn}\end{array}$ & A \\
\hline & & 130703 & Other fuels (including mixtures) & $\mathrm{Cd}, \mathrm{Be}, \mathrm{Sb}, \mathrm{Se}$ & A \\
\hline & $\begin{array}{c}1308 \\
\text { oil wastes not } \\
\text { otherwise specified }\end{array}$ & 130899 & Wastes not otherwise specified & $\mathrm{Cr}^{6+}$ & A \\
\hline
\end{tabular}

a) Absolute Entry

b) Mirror Entry

중 51건을 대상으로 하여 미규제 유해물질인 $\mathrm{Ba}, \mathrm{Be}$, $\mathrm{Ni}, \mathrm{Sb}, \mathrm{Se}, \mathrm{V}, \mathrm{Zn}, \mathrm{F}$ 항목에 대한 함량 분석을 수행하 였으며, 그 결과는 Fig. 2 및 Table 4에 나타내었다.

미규제 유해물질 8종에 대한 함량 분석 결과, $\mathrm{EWC}$ (13 01) 공정에 해당하는 폐유압유에서 산술평균값으 로 $\mathrm{Be} 13 \mathrm{mg} / \mathrm{kg}, \mathrm{Sb} 127 \mathrm{mg} / \mathrm{kg}, \mathrm{Se} 67 \mathrm{mg} / \mathrm{kg}$ 이었으 며, 각 항목의 제안 기준 $(\mathrm{Be} 5 \mathrm{mg} / \mathrm{kg}, \mathrm{Sb} 50 \mathrm{mg} / \mathrm{kg}$, $\mathrm{Se} 50 \mathrm{mg} / \mathrm{kg}$ )을 초과 하였다. 또한 $\mathrm{EWC} 1302,13$ 03 공정 또한 동일하게 $\mathrm{Be}, \mathrm{Sb}, \mathrm{Se}$ 항목이 초과하였으
며, EWC 13 05(유수분리기 함유물)공정은 $\mathrm{Be} 14 \mathrm{mg}$ / $\mathrm{kg}$, Ni $578 \mathrm{mg} / \mathrm{kg}, \mathrm{Sb} 76 \mathrm{mg} / \mathrm{kg}, \mathrm{V} 205 \mathrm{mg} / \mathrm{kg}, \mathrm{Zn}$ $2,423 \mathrm{mg} / \mathrm{kg}$ 으로 나타났다. 그리고 폐액상 연료폐기물 (EWC 1307$) 6$ 개 시료의 분석결과 $\mathrm{Be}(1,395 \mathrm{mg} / \mathrm{kg})$, $\mathrm{Ni}(4 \sim 2,374 \mathrm{mg} / \mathrm{kg}), \mathrm{Sb}(103 \sim 175 \mathrm{mg} / \mathrm{kg}), \mathrm{Se}$ (40 109 mg/ $\mathrm{kg}), \mathrm{Zn}(0 \sim 14,792 \mathrm{mg} / \mathrm{kg})$ 의 농도 범위를 나타냈다. EWC 13 08(기타 불특정 유류 폐기물) 공정은 제안기 준을 초과한 시료는 없었다.

공정별 미규제 무기물질의 초과항목으로는 $\mathrm{EWC}$ 
1301 공정 5 항목 $(\mathrm{Be}, \mathrm{Sb}, \mathrm{Se}, \mathrm{V}, \mathrm{F}), \mathrm{EWC} 1302$ 공 정 4항목 $(\mathrm{Be}, \mathrm{Sb}, \mathrm{Se}, \mathrm{Zn}), \mathrm{EWC} 1303$ 공정 5항목 $(\mathrm{Be}, \mathrm{Ni}, \mathrm{Sb}, \mathrm{Se}, \mathrm{Zn}), \mathrm{EWC} 1304$ 공정 3항목 $(\mathrm{Be}, \mathrm{Sb}$, $\mathrm{Se}), \mathrm{EWC} 1305$ 공정 7 항목 $(\mathrm{Ba}, \mathrm{Be}, \mathrm{Ni}, \mathrm{Sb}, \mathrm{Se}, \mathrm{V}$, $\mathrm{Zn}), \mathrm{EWC} 13$ 07공정 7항목( $\mathrm{Ba}, \mathrm{Be}, \mathrm{Ni}, \mathrm{Sb}, \mathrm{Se}, \mathrm{V}$, $\mathrm{Zn}), \mathrm{EWC} 1308$ 공정에서는 미규제 무기물질이 초과 하는 항목은 없었다. 또한 제안기준을 초과한 사업장 폐기물과 항목은 기계유 $(\mathrm{Sb}, \mathrm{Se}, \mathrm{Be})$, 작동유 $(\mathrm{Be}, \mathrm{Se}$, $\mathrm{Sb}, \mathrm{Zn})$, 절연유 $(\mathrm{Be}, \mathrm{Ni}, \mathrm{Se}, \mathrm{Sb}, \mathrm{V})$, 선저유 $(\mathrm{Be}, \mathrm{Se}$, $\mathrm{Sb})$, 연료유 $(\mathrm{Ba}, \mathrm{Be}, \mathrm{Ni}, \mathrm{Se}, \mathrm{Sb}, \mathrm{V}, \mathrm{Zn})$, 절삭유 $(\mathrm{Be}$, $\mathrm{Se}, \mathrm{Sb})$ 이다.

\section{3. 폐유 및 액상연료 폐기물의 목록화}

$\mathrm{EWC}$ 에서 규정한 7단계 유해폐기물 평가기법을 활 용하여 폐기물을 절대유해폐기물(Absolute Entry)과, 상대유해폐기물(Mirror Entry), 그리고 유해특성으로 판단이 필요한 폐기물, 3 개의 목록으로 구분하였다. ${ }^{14}$ $\mathrm{EU}$ 의 폐기물 7단계 평가기법을 통해 유해폐기물과 비유해폐기물로 구분하며, 1 단계에서는 EU Waste Directive에 등록된 폐기물인가, 2 단계 및 3 단계에서 는 $\mathrm{EU}$ 국가 환경부 등의 기관에서 유해하다고 판단하 거나 비유해하다고 지정한 폐기물 조작 과정에서 배 출된 폐기물인가, 4 단계는 $\mathrm{EWC}$ 폐기물 목록인가, 5 단계는 폐기물이 어떤 성분을 함유하고 있는가, 6 단 계는 함유된 성분이나, 분석에 의하여 결과로 나타난 성분이 유해한 경우에는 7 단계로, 비유해한 경우에는 비유해 폐기물로 판정한다. 또한 마지막 7 단계는 폐 기물이 함유한 유해성분이 H1 H15 (H1:폭발성, H2:산 화성, $\mathrm{H} 3 \mathrm{~A}$ : 고도인화성, $\mathrm{H} 3 \mathrm{~B}$ : 인화성, $\mathrm{H} 4$ : 자극성, $\mathrm{H} 5$ : 위해성, H6: 독성, H7: 발암성, H8: 부식성, H9: 감염성, H10: 재생성시독성, $\mathrm{H} 11$ : 변이원성, $\mathrm{H} 12$ : 물 이나 공기 및 산과 접촉 시 독성을 방출, H13: 민감성, $\mathrm{H} 14$ 생태독성, H15: 폐기 후 위에 언급된 특성을 보 이는 물질)에 해당하는 가의 여부를 통해 판단한다. ${ }^{15}$ $\mathrm{EWC}$ 판정 절차를 통해 국내 폐유 및 액상연료 공정 에서 발생된 폐기물을 판정한 결과는 Table 5와 같다. 국내 지정폐기물에 함유된 유해물질에 해당하는 항목 이 초과한 절대유해폐기물 공정이 16 개, 향후에 관리 가 필요한 미규제 유해물질이 초과된 상대유해폐기물 공정은 8 개로 판단된다.

\section{4. 결 론}

본 연구에서는 국내 지정폐기물 공정의 배출특성을
파악하고자 폐유 및 액상연료 공정을 대상으로 무기 물질류의 함량특성을 조사하여 다음과 같은 결론을 내렸다.

1. 규제대상 무기물질류의 함량분석결과, $\mathrm{EWC} 13$ 03 (폐절연유, 폐열전달유)공정은 $\mathrm{Cd} \mathrm{16,934,911} \mathrm{mg/}$ $\mathrm{kg}, \mathrm{Cu} 430 \mathrm{mg} / \mathrm{kg}, \mathrm{Pb} 102 \mathrm{mg} / \mathrm{kg}, \mathrm{CN} 366 \mathrm{mg} / \mathrm{kg}$ 의 농도로 조사되었고, $\mathrm{EWC} 13$ 05공정은 유수분리시 발 생한 폐기물로 $\mathrm{Cu}(414 \mathrm{mg} / \mathrm{kg})$ 의 농도가 가장 높게 검출되었다.

2. 미규제 유해물질 8 종에 대한 함량분석결과, $\mathrm{EWC}(13$ 01) 공정에 해당하는 폐유압유에서 $\mathrm{Be} 13$ $\mathrm{mg} / \mathrm{kg}, \mathrm{Sb} 127 \mathrm{mg} / \mathrm{kg}, \mathrm{Se} 67 \mathrm{mg} / \mathrm{kg}$ 의 산술평균값으 로 조사되었으며, $\mathrm{EWC} 1305$ (유수분리기 함유물)공 정은 $\mathrm{Be} 14 \mathrm{mg} / \mathrm{kg}, \mathrm{Ni} 578 \mathrm{mg} / \mathrm{kg}, \mathrm{Sb} 76 \mathrm{mg} / \mathrm{kg}, \mathrm{V}$ $205 \mathrm{mg} / \mathrm{kg}, \mathrm{Zn} 2,423 \mathrm{mg} / \mathrm{kg}$ 으로 나타났다.

3. $\mathrm{EWC}$ 판정 절차를 통해 국내 폐유 및 액상연료 공정에서 발생된 폐기물을 판정한 결과, $\mathrm{EWC}$ 중분류 24개 공정 중 절대유해폐기물(Absolute Entry)공정은 16 개, 상대유해폐기물(Mirror Entry) 공정은 8 개로 판 단된다.

\section{참고문헌}

1. National Institute of Environmental Research, 'A Study on Hazardous Waste Catalogue and Discharging Characteristics (IV)', 2011.

2. National Institute of Environmental Research, 'A Study on Hazardous Waste Catalogue and Discharging Characteristics (V)', 2012.

3. Ministry of Environment Korea, Wastes Contol Act, 2011.

4. US EPA, 'RCRA Orientation Manual', 2006.

5. EU, 'Interpretation of the definition and classification of hazardous wastes (2nd edition v2.3)', Environment Agency, 2011.

6. KECO, Allbaro System, 2011.

7. Ministry of Environment Korea, Waste processing methods, 2011.

8. National Institute of Environmental Research, 'Standardization of Test Methods for Unregulated Hazardous Substances in Wastes(Inorganics) (I)', 2008.

9. National Institute of Environmental Research, 'Extension the Regulation Items of Unregulated Hazardous Substances in Specified Waste (I)', 2006. 
10. National Institute of Environmental Research, 'Extension the Regulation Items of Unregulated Hazardous Substances in Specified Waste (II)', 2007.

11. Kim, W.-I. and Jeong, S.-K., 'Leaching and Contents Characteristics of Regulated Heavy Metals in Hazardous Waste from the Paint Industry in Korea', 29, 121129 (2012).

12. Jeon, T.-W. and Lee, D.-J., 'A study on the characteristics of substances for hazardous waste from organic industries', Korea Society of Waste Management, 27, 95-103 (2010).
13. Lee, Y.-W., Cho, D.-C., Hong, N.-P., 'A Study of the Electrical Properties of Transformer Oils', Transaction on Electrical and Electronic Materials (1995).

14. Jeong, S.-K. and Kim, W.-I., 'Study of Leaching Behavior on Dust Produced from Metal Manufactruing Processes', 29, 642-649 (2012).

15. Kim, D.-U., Kang, Y.-Y. and Lee, D.-J., 'Content Characteristics of Organic Pollutants Waste from Paint, Iron making and Steel making Process', Analytical science \& technology, 24, 395-400 (2011). 